\title{
Enseñando a las niñas a consumir. La revista infantil Marilú (1933-1937) ${ }^{1}$
}

\section{Teaching girls to consume. Marilú Child magazine (1933-1937)}

\author{
María Paula Bontempo \\ Instituto Interdisciplinario de Estudios de Género \\ Universidad de Buenos Aires \\ Universidad Nacional Arturo Jauretche \\ (Argentina) \\ paubontempo@yahoo.com.ar
}

Hacia finales de 1932, la muñeca "Marilú" se presentó en el mercado argentino por primera vez. Para promocionarla, se emplearon una serie de estrategias entre las que se destacó la publicación de la revista Marilú, la mejor amiga de las niñas. En este artículo abordaré la relación entre la muñeca "Marilú" y el semanario Marilú, pero concentrándome, fundamentalmente, en este último. El período elegido abarca desde la aparición del magazine para las niñas, en 1933, hasta el momento en que se transformó en un mensuario de modas para mujeres adultas, en 1937. En las siguientes páginas se analizará la revista en sus distintas dimensiones. Por un lado, como una publicación con varios objetivos, entre ellos, la publicidad de "Marilú" y sus accesorios, la construcción de una comunidad de lectoras-consumidoras y la consolidación de una guía de consumo de la muñeca. Por otro lado, como un magazine que era un objeto de consumo en sí mismo y que, por lo tanto, buscaba permanecer en el mercado. Finalmente, en consonancia con otros discursos, se explorará a la revista como un manual para aprender los roles que se suponía correspondían a las mujeres.

Palabras Clave: Revista infantil - Muñeca - Consumo - Género

1. Este trabajo nació en el marco de las I Jornadas de Jóvenes Investigadorxs y Tesistas del Instituto Interdisciplinario de Estudios de Género (FFyL-UBA) realizadas el 19 de agosto de 2011. Agradezco la intervención de Ana Laura Martín en esa oportunidad. Cuando esa ponencia tomó forma de artículo, los comentarios de Inés Pérez han sido de gran valor así como los recibidos por parte de los miembros del Taller de Historia de los Medios, coordinado por Sylvia Saítta y Lila Caimari. También agradezco las sugestivas, agudas y estimulantes observaciones de los integrantes del Grupo de Trabajo Historia de las Familias y las Infancias, dirigido por Isabella Cosse (IIEGE-UBA). 


\begin{abstract}
By the end of 1932, the doll "Marilü" was introduced in the argentinian market for the first time. So as to promote it, a number of strategies were used, among which, the publication of the magazine Marilu, la mejor amiga de las niñas (Marilu, the gilrs'best friend) stands out. In this article, I will approach the relationship between the doll "Marilú" and the weekly magazine Marilú, but fundamentally focusing on the last one. The selected period covers from the appearance of the magazine for the girls, in 1933, up to the moment it became a monthly fashion magazine for adult women, in 1937. In the following pages, the magazine will be analyzed in its different dimensions. On one side, as a publication with several objectives, for instance, the advertising of "Marilú" and its accessories, the construction of a community of reader-consumer girls and the consolidation of the doll's consumer guide, among others. On the other side, as a magazine which was a consumer item in itself and that, therefore, was seeking to stay in the market. Finally, in accordance with other discourses, the magazine will be examined as a manual of the roles that, supposedly, corresponded to women.
\end{abstract}

Key Words: Children’s Magazine - Doll - Consumption - Gender

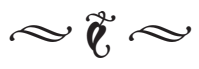

\section{Introducción}

“¡Ahj! ¡Lo que era tener una 'Marilú'” con esta frase, a medio camino entre el suspiro y resoplo, Nelcy, de 69 años recordaba aquello que le hubiese gustado poseer de niña: una muñeca "Marilú". Otras muñecas se podían hacer, otras muñecas se podían comprar pero ella no quería una de esas, quería la que tenía nombre propio: "una Marilú". ${ }^{2}$ Cuando Nelcy era pequeña, a mediados de los años cuarenta, la muñeca ya estaba instalada en el mercado, ya era famosa y deseada por miles de niñas. A 82 años de la presentación en sociedad de "Marilú", la "amiga inseparable de las niñas", sigue siendo una de las muñecas más famosas y recordadas en Argentina.

2. Entrevista a Nelcy, Buenos Aires, Diciembre de 2009.
En este artículo abordaré algunas de las estrategias comerciales que posibilitaron el éxito de "Marilú", poniendo el foco, principalmente, en la publicación que acompañó el lanzamiento del producto. La relevancia de detenerme en la revista Marilú reside en que no sólo fue un vehículo para darle publicidad a la muñeca, sino también -como las publicidades actuales que aparecen en televisión- un artefacto que le dio sentido al juguete y constituyó una guía de consumo, en cuanto a desear, comprar, jugar, conocer, comprender, cuidar, limpiar y transformar la "amiguita de las niñas". ${ }^{3}$ Simultáneamente, el magazine de Editorial Atlántida fue un objeto

3. MINZI, Viviana, "Los chicos según la publicidad. Representaciones de infancia en el discurso del mercado de productos para niños", en CARLI, Sandra, La cuestión de la infancia. Entre la escuela, la calle y el shopping, Paidós, Buenos Aires, 2009, pp. 209-240. 
de consumo en sí mismo -que por lo tanto pretendía permanecer en el mercado- y un manual del deber ser femenino infantil. Estas múltiples dimensiones serán exploradas desde la presentación del semanario en el mercado, en 1933, hasta 1937, momento en que se transformó en un mensuario de modas para mujeres adultas.

Partiendo de aportes previos, en las páginas siguientes abordaré la revista Marilú a partir de un análisis histórico y desde una perspectiva de consumo que permitirá indagar en la construcción del "niño consumidor" en las primeras décadas del siglo veinte. ${ }^{4}$ Ahondar en una revista para niñas editada en la década del treinta del siglo pasado y organizada alrededor de un producto puede funcionar como una lente para comenzar a estudiar la construcción de una cultura infantil atravesada por el mercado, la difusión de modelos estéticos y de clase, la circulación de valores y de formas de sociabilización infantil. En este sentido, estimo que explorar Marilú contribuye a iluminar la historia de la infancia y la familia, de los medios de comunicación y del consumo en Argentina. ${ }^{5}$

Partiendo de la consideración de que el "niño consumidor" es una construcción compleja, en este trabajo examinaré la revista Marilú

4. PELEGRINELLI, Daniela, "Prodigiosa Marilú", en A boca de sapo. Revista de arte, literatura y pensamiento, Tercera Época, Pilar, 2011, Año XII, No 9, pp. 14-19.

5. CARLI, Sandra, "El campo de estudios sobre la infancia en las fronteras de las disciplinas. Notas para su caracterización e hipótesis sobre sus desafíos" en COSSE, Isabella, LLOBET, Valeria, VILLALTA, Carla, ZAPIOLA, María Carolina (editoras) Infancias: politicas y saberes en Argentina y Brasil: siglos XIX y XX, Teseo, Buenos Aires, 2011, pp.31-55. desde distintos ángulos. ${ }^{6}$ En primer lugar, pondré en relación la revista infantil femenina con Billiken -un magazine infantil publicado por Editorial Atlántida con catorce años de presencia en el mercado. La importancia de introducir en estas páginas a Billiken radica en que, por un lado, éste contribuyó, desde sus comienzos, a instalar el consumo de juguetes en general y muñecas en particular; y por el otro, sirvió de modelo para la revista Marilú. En segundo lugar, analizaré Marilú como un conjunto de páginas destinadas a publicitar la muñeca al mismo tiempo que como un objeto de consumo en sí mismo. Así, tanto la revista como la muñeca desarrollaron una serie de estrategias que las retroalimentaba, entre ellas la organización de festivales, ferias y concursos. En este sentido, la identificación de la revista con los valores católicos también parece ser una opción tendiente a afianzar la publicación en el mercado. Finalmente, y en relación con este último aspecto, consideraré cómo la publicación, mientras enseñaba a consumir jugando, también funcionaba a como un compendio para aprender los roles que se suponía correspondían a las mujeres.

6. COOK, Daniel, The Commodification of Childhood. The Children's Clothing Industry and the Rise of the Child Consumer, Duke University Press, Durham, 2004, JACOBSON, Lisa, Raising Consumers. Children and the American Mass Market in the Early Twentieth Century, Columbia University Press, New York, 2004; SOSENSKI CORREA, Susana, "El niño consumidor: una construcción publicitaria de mediados de siglo XX", en ACEVEDO, Ariadna, LÓPEZ CABALLERO Paula (coordinadores) Ciudadanos inesperados. Procesos de formación de la ciudadania ayer y hoy, El Colegio de México / CINVESTAV, Departamento de Investigaciones Educativas, México, 2012, pp. 191-222. 


\section{Billiken prepara el mercado}

En el momento en que apareció Billiken (1919) los niños ya estaban en el centro de diversos discursos, imágenes y representaciones que atravesaban, y trataban de regular, la vida familiar al tiempo que se acentuaba, en un grado sin precedentes, una cultura familiar centrada en los hijos. Así, la infancia comenzó a ser valorada como una etapa idílica. ${ }^{7}$ De manera que los cambios que se produjeron en el interior de la familia debieron ser negociados en la medida que había que redefinir la manera de comportarse, sentir y presentarse. ${ }^{8}$

Localmente, este proceso se enlaza con un fenómeno constitutivo de la sociedad y de la cultura argentinas, es decir la Ley 1420 (1884), que sentó las bases para la educación obligatoria, laica y gratuita. Como señala Sandra Carli, la escolarización operó como un factor de homogeneización de identidades y de socialización de las generaciones adultas "favoreciendo una configuración del niño como un sujeto que desbordaba los núcleos familiares y los sectores sociales de origen". ${ }^{9}$

7. POLLOCK, Linda, "Las relaciones paternofiliales", en KERTZER, David I., BARBAGLI, Marzio, Historia de la Familia Europea. La Vida Familiar a Principios de la Era Moderna (1500-1789), V. I Paidós, Barcelona, 2001.

8. MAYNES, Mary Jo, "Culturas de clase e imágenes de la vida familiar correcta”, en KERTZER, David I., BARBAGLI, Marzio, Historia de la Familia Europea. La Vida Familiar desde la Revolución Francesa hasta la Primera Guerra Mundial (1789-1913), V. II, Paidós, Barcelona, 2002.

9. CARLI, Sandra, Niñez, Pedagogía y Politica. Transformaciones de los Discursos acerca de la Infancia en la Historia de la Educación Argentina entre 1880 y 1955, Miño y Dávila, Buenos Aires, 2005, p. 40.

110
Al mismo tiempo, "la difusión masiva de la escolaridad potenciaba las demandas familiares y un acceso a los nuevos saberes sobre el niño", entre los que se encontraban los discursos pedagógicos y los avances en psicología infantil. ${ }^{10}$ A partir de allí, se iría consolidando una sensibilidad favorable a la infancia que finalmente se transformó en una "entronización de los niños" y que alcanzará su mayor intensidad a mediados del siglo veinte. ${ }^{11}$

Sobre estos cambios, negociaciones, discursos y sensibilidades se asentó Billiken, la revista de los niños. Esta publicación destinada a los chicos constituyó un emprendimiento de Constancio C. Vigil, escritor, periodista y empresario de origen uruguayo y de una importante trayectoria en la dirección y edición de revistas. Billiken fue la tercera publicación de la recientemente conformada Editorial Atlántida -que editaba Atlántida (1918) y El Gráfico (1919)- pero no la primera experiencia del director en publicaciones infantiles, debido a que quince años antes había lanzado al mercado, sin mucha suerte, Pulgarcito (1904), el primer magazine para niños en Argentina. ${ }^{12}$ Billiken tampoco sería la única publicación que dedicara a los niños ya que luego del alejamiento de la dirección de la revista en 1925- aunque no del manejo de la empresa- se especializó en la escritura de libros y cuentos infantiles, algunos de ellos utilizados en la escuela, como el recordado Marta y Jorge (1927), y otros donde surgieron algunos de sus

10. Ídem, p. 199.

11. COSSE, Isabella, Estigmas de nacimiento. Peronismo y orden familiar. 1946-1955, FCE-UdeSa, Buenos Aires, 2006, pp. 104-111.

12. SZIR, Sandra M., Infancia y cultura visual. Los periódicos ilustrados para niños (1880-1910), Miño y Dávila, Buenos Aires, 2006. 
personajes más famosos, entre ellos el Mono Relojero y la Hormiguita Viajera.

Pensando en sus lectores como niños pertenecientes a los sectores sociales en ascenso, Billiken destinó material para ambos sexos, desde notas de interés general y artículos escolares -que en ocasiones competían con los saberes transmitidos por la institución oficial- hasta cuentos e historietas. ${ }^{13} \mathrm{Y}$ si bien la revista buscaba como interlocutores a los "niños-alumnos-hijos" -de acuerdo a diversas construcciones culturales que circulaban desde el ámbito judicial y el pedagógico hasta el periodístico y el político- en sus páginas daba cuenta de diferentes facetas de ese modelo. ${ }^{14}$ Así, en el reconocimiento de la heterogeneidad de intereses y en la complejización de la infancia que intentó construir como ideal residen algunas de las claves del triunfo de la publicación. ${ }^{15}$

Desde sus orígenes Billiken dio voz y acción

13. VARELA, Mirta, Los hombres ilustres de Billiken. Héroes en los medios y en las escuelas, Colihue, Buenos Aires, 1994.

14. En este trabajo se considera que las categorías de "niños, hijos-alumnos y menores" son construcciones culturales. Sobre esta construcción ver: LIONETTI, Lucía, MÍGUEZ, Daniel "Aproximaciones iniciales a la infancia”, en LIONETTI, Lucía, MíGUEZ, Daniel (compiladores) Las infancias en la historia argentina. Intersecciones entre prácticas, discursos e instituciones (18901960), Prohistoria, Rosario, 2010, pp. 9-32; ZAPIOLA, María Carolina, "Los niños en las calles: imágenes literarias y representaciones oficiales en la Argentina del Centenario", en GAYOL, Sandra, MADERO, Marta (editoras) Formas de historia cultural, Prometeo/UNGS, Buenos Aires, 2007, pp. 205-332.

15. BONTEMPO, María Paula, "Los niños de Billiken. Las infancias en Buenos Aires en las primeras décadas del siglo XX", en Anuario del Centro de Estudios Históricos "Prof. Carlos S. A. Segreti, Córdoba, 2012, año 12, № 12, pp. 205-221. a los niños haciéndolos participar en diversas secciones como "¿Qué buena obra hizo usted en la semana última?” al mismo tiempo que orientaba espacios destinados a indagar en los deseos infantiles y a reconocer a los niños como potenciales consumidores. Así, junto con las "buenas obras", aparecieron los apartados “¿En que gastará los 5 pesos?” o “¿Qué quiere que le regale sus papás y por qué?” En las respuestas publicadas aparecían desde libros, juegos de ajedrez, juguetes y muñecas hasta cámaras fotográficas y cinematográficas, joyas, pianos o "manomóviles". Algunos de estos productos fueron publicitados en la revista muy tempranamente y otros aparecieron en ella a medida que el magazine se afianzaba en el mercado y se convertía en un medio confiable y estable para publicitar.

La idea del juguete como parte del universo infantil -que se empezó a consolidar en las primeras décadas del siglo veinte y que forma parte de la construcción de una cultura de la infancia- estuvo presente en Billiken desde el primer número. ${ }^{16}$ Es decir que la revista, desde esta perspectiva, tuvo un lugar destacado en una trama cultural compleja -que abarcaba desde

16. Hacia al final de la década del veinte, Walter Benjamin advierte sobre la historicidad de los juguetes como productos de y para la infancia. Al respecto ver: BENJAMIN, Walter, Reflexiones sobre niños, juguetes, libros infantiles, jóvenes y educación, Nueva Visión, Buenos Aires, 1974 (1928). Algunas de sus ideas serán retomadas por Philippe Ariès en su interpretación sobre la invención del nuevo sentimiento de infancia en el siglo XIX. ARIÈS, Philippe, El niño y la vida familiar en el Antiguo Régimen, Taurus, Madrid, 1987 (1960). Un excelente estado de la cuestión sobre la naturalización de los juguetes como partes del mundo infantil -que además incorpora los estudios sobre la etnotecnología del juegopuede encontrarse en RUSTOYBURU, Cecilia, "Jugando a la mamá en los tiempos de la revolución sexual. Los consejos psi sobre juegos y juguetes en los años 1960", en LIONETTI, Lucía, MÍGUEZ, Daniel (compiladores) Las infancias en la historia..., Op. Cit., pp. 216-236. 
las vanguardias estéticas, literarias y diversas industrias hasta los discursos pedagógicos y judiciales- que ponía en escena demandas sociales "entre las que figuraba el reclamo de un mayor acceso de los niños a los productos de la modernidad". ${ }^{17}$ Entre esos productos no sólo pueden mencionarse los juguetes sino también el deseo y la posibilidad de consumirlos.

El número inicial de Billiken, -cuya tapa fue la imagen de un niño con una pelota de cuero bajo el brazo y todo maltrecho luego de un partido de fútbol- contenía un juguete de papel que consistía en una figura para recortar y armar; publicitaba, entre otros anuncios, el Gran Bazar y Juguetería Era; daba espacio a un cuadro humorístico del pintor argentino Oscar Soldati -que retrataba a un niño repleto de juguetes pero inconforme- y a un texto explicando los Juegos y juguetes del Japón. También incluía un breve artículo a cargo de Isabel Creus sobre qué juguetes convenían a los niños. En ese escrito, la autora, quien también participó de la Encuesta Feminista Argentina (1919), sugiere juguetes "divertidos y de utilidad", para referirse a aquellos que hoy se identifican como pedagógicos, los cuales podían ser confeccionados de forma casera. Allí también recomendaba "cochecitos de muñecas...y muñecas con vestiditos que se abrochen, desabrochen y puedan quitarse [pues] habituarán a las niñas a vestirse y desvestirse por sí solas". ${ }^{18}$ Introducir la

17. CARLI, Sandra, Niñez, Pedagogía y Política..., Op. Cit., p. 199.

18. CREUS, Isabel, “¿Qué juguetes convienen a los niños?”, en Billiken, Buenos Aires, 1919, Año 1, № 1, 17-11, p. 34. Décadas después, las recomendaciones sobre juegos y juguetes para niños y niñas serían dictadas por especialistas del psicoanálisis. Al respecto ver: RUSTOYBURU, Cecilia, "Jugando a la mamá...", Op. Cit. En México puede apreciarse un proceso similar. importancia y "universalidad" de los juguetes en la infancia era una información para los niños y para los adultos, que eran quienes realmente comprarían los juguetes si se los convencía de que constituían una "necesidad" infantil.

La inclusión de la publicidad en Billiken fue diversa y elaborada, en especial, si se la compara con su antecesora Pulgarcito. En el marco del desarrollo que estaba experimentando el mercado, el consumo y la publicidad en Argentina, ${ }^{19}$ el magazine introdujo publicidad encubierta en sus páginas ilustradas. Por ejemplo, en una fotografía titulada "Niñas Laboriosas", puede verse a un grupo de niñas jugando con muñecas y una máquina de coser. La primera impresión responde a una imagen identificada con el "deber ser" de las niñas como futuras mujeres adiestradas en las habilidades hogareñas. Pero si nos detenemos en el epígrafe que acompaña la foto aclara que ese artefacto había sido adquirido en la casa Anderson y Kay en la calle Maipú No $47 .{ }^{20}$ $\mathrm{La}$ foto publicitaria es interesante porque, en primer lugar, funde el material ofrecido por la revista -en sí mismo un objeto de consumocon los artículos promocionados, desdibujando el límite entre los contenidos y la publicidad.

SOSENSKI, Susana, "Producciones culturales para la infancia mexicana: los juguetes (1950-1960), en Relaciones, Michoacán, 2012, o 132, pp. 95-126.

19. ROCCHI, Fernando, "Consumir es un placer: la industria y la expansión de la demanda en Buenos Aires a la vuelta del siglo pasado", en Desarrollo Económico, Buenos Aires, 1998, V. 37, № 148, pp. 553-558; ROCCHI, Fernando, "Inventando la soberanía del consumidor: publicidad, privacidad y revolución del mercado en Argentina, 1860-1940", en DEVOTO, Fernando, MADERO, Marta (directores) Historia de la vida privada en Argentina. La Argentina plural (18701930), T. II, Taurus, Buenos Aires, 1992, pp. 301-321.

20. Billiken, Buenos Aires, 22-03-1920. 
En segundo lugar, comienza a construir y definir un mundo que es propio de la infancia porque, a diferencia de las publicidades que incluían a los niños como consumidores de dulces, galletitas y golosinas -productos que finalmente podía consumir toda la familia-, "Niñas Laboriosas" incluye a las pequeñas como consumidoras activas y exclusivas de objetos que se supone para ellas: los juguetes. ${ }^{21}$

$\mathrm{Al}$ igual que los pisos de las tiendas Harrods y Gath E' Chaves, la Casa Burlando -El Palacio de los Juguetes, que publicitaba con frecuencia en Billiken, estaba abarrotada de muñecas, artefactos domésticos en pequeña escala, animalitos y triciclos; de trenes cajas de construcciones de madera, soldaditos y "Meccano". Aunque existían algunos establecimientos nacionales dedicados a la fabricación de estos objetos, hasta mediados del siglo veinte la mayoría eran importados de Alemania e Inglaterra. El impulso a la industria juguetera llegaría recién en los años cuarenta, como producto de la disminución de las exportaciones de los países productores y del aliento que los gobiernos peronistas le darían -en el marco de la promoción de la industria nacional y del consumo-, a través de la compra masiva y reparto de juguetes desde el Estado, cuyo objetivo sería "equiparar" las diferencias sociales cristalizadas a través de los objetos. ${ }^{22}$ De manera que la mayoría

21. ROCCHI, Fernando, "Inventando la soberanía del consumidor...”, Op. Cit.

22. PELEGRINELLI, Daniela, Diccionario de Juguetes Argentinos. Infancia, Industria y Educación 1880-1965, El juguete Ilustrado Editor, Buenos Aires, 2010, pp. 1520,182-187; ELENA, Eduardo, Dignifying Argentina. Peronism, Citizenship and Mass Consumption, University of Pittsburgh Press, Pittsburgh, 2011. MILANESIO, Natalia, Cuando los trabajadores salieron de compras. Nuevos consumidores, publicidad y cambio cultural durante el peronismo, Siglo XXI, Buenos Aires, 2014; CARLI, de los juguetes publicitados por las grandes tiendas -o por otros negocios destinados a venderlos- en los años veinte y treinta era poco accesible para los lectores de Billiken, aunque no imposible, ya que los sectores medios tenían cierta posibilidad de comprar algunos -probablemente contados y únicos para sus poseedores- de estos bienes en el mercado. ${ }^{23}$ Sin embargo, independientemente de si los niños pudiesen o no adquirirlos en una juguetería, los juguetes formaban parte del mundo de la revista y del mundo infantil que proponía el semanario. Mientras las revistas y las grandes tiendas homogeneizaban el deseo y creaban una comunidad de niños con ciertas aspiraciones, también acentuaban las diferencias sociales. ${ }^{24}$ Esta paradoja sería subrayada cuando Billiken publicite la muñeca "Marilú". El caso de las muñecas, como parte del juego infantil y del mundo femenino, tuvo un lugar privilegiado en el semanario. Sobre todo porque no sólo fomentaba la compra sino también el préstamo, el uso, la circulación, la confección de accesorios y el embellecimiento del juguete.

Estas formas de consumo aparecieron plasmadas en el "Concurso Billiken de las cien muñecas" en el cual estaban involucradas no sólo la revista, las lectoras y las dueñas de las muñecas sino también los comercios, los escolares y las niñas sin recursos. El concurso comprendía varias instancias. Primero, los

Sandra, "Los únicos privilegiados son los niños", en Todo es Historia, Buenos Aires, 2005, V. 457 pp. 58-65; COSSE, Isabella, Estigmas..., Op. Cit., pp. 112-116.

23. CIAFARDO, Eduardo, Los niños en la ciudad de Buenos Aires (1890-1910), Buenos Aires, CEAL, 1992, pp. 9; 24-35.

24. Para la sociedad mexicana de mediados del siglo veinte ver: SOSENSKI CORREA, Susana, "El niño consumidor...", Op. Cit. 
comercios o a las lectoras donarían muñecas. Segundo, éstas serían enviadas a escuelas de la Capital Federal a fin de que un grupo de niñas "designadas" por la directora vistiesen a las muñecas como quisieran -con trajes de calle, de fantasía, de época o disfrazadas. Tercero, esas muñecas se expondrían en la tienda masculina "Casa Álvarez" y se rematarían con fines benéficos. Con el dinero recaudado se compraría juguetes para ser repartidos en asilos y hospitales. Las niñas que vivían en el interior del país podrían participar enviando una muñeca ya vestida. Posteriormente, se premiaría los mejores treinta vestidos con una medalla de plata, una de bronce, un objeto de arte, estuches de labores y pulseritas. ${ }^{25}$ Finalmente el remate no se realizó, las muñecas fueron rifadas y lo recaudado se destinó a la "Copa de Leche" u otros fines filantrópicos. ${ }^{26}$

Este concurso es interesante porque en primer lugar involucró a la agencia publicitaria, a diversos actores -la revista, las lectoras, las niñas que vestirían las muñecas, los potenciales compradores- y distintas instituciones -escuelas, asilos y hospitales. En segundo lugar, el concurso conjugó la adquisición y donación de las muñecas y estimuló el consumo, la circulación y el uso de las mismas entre diversos sectores sociales. Por último, sancionó un espacio femenino propio en la revista relativa a las "labores"-bordar y coser- y a las acciones de beneficencia como actividades de la esfera pública permitidas, aceptadas y estimuladas en las niñas y posteriormente en las mujeres.

Si bien el semanario era para todos los niños y las niñas, como hemos visto, algunos concursos y ciertas secciones estaban

25. Billiken, Buenos Aires, 03-10-1921.

26. Billiken, Buenos Aires, 26-12-1921.

114 divididos por género. Aunque por supuesto podía ser leído por chicas y chicos, la serie "Emociones Futbolísticas" (1931), que giraba en torno a un equipo barrial, parece dirigida a varones. Mientras que "La Hermana Mayor" (1928) -que enseñaba a realizar quehaceres domésticos- estaba dedicada a la educación femenina. En esta última se inscribió Marilú, una nueva sección de Billiken que apareció en noviembre de 1932, coincidiendo con el decimocuarto aniversario de la publicación. Pero esta vez, la columna fue acompañada con el lanzamiento de una muñeca de nombre homónimo que pasó a formar parte de la cultura de la infancia y quedó en el recuerdo de miles de mujeres que fueron niñas durante las décadas del treinta, cuarenta y cincuenta.

\section{Una muñeca con trajecitos y accesorios}

La muñeca "Marilú" no fue el primer producto que se acompañó con una revista en Argentina. Muy tempranamente Pulgarcito invitaba a cambiar el semanario por las Pastillas Rosadas de Williamson que se vendían en la Farmacia Inglesa D. Nelly. Tampoco Marilú fue la primera revista que acompañó un producto. Por ejemplo, Colibrí (1920) era una publicación escolar, editada por la fábrica de cafés y chocolates Saint Hnos., destinada a promover el consumo de Chocolates Águila. En sus páginas se enseñaba a usar los productos y se anunciaba los nuevos, por ejemplo los "Colibrí de Chocolate" así como se estimulaba a cambiar los envoltorios de "Aguila Express" por obsequios. ${ }^{27}$ De manera que antes de que apareciera la revista Marilú,

27. Colibrí, Buenos Aires, 15-03-24; Colibrí, Buenos Aires, 01-04-1924; Colibrí, Buenos Aires, 06/1923. 
existían antecedentes y experiencias en asociar productos con revistas, en invitar a los niños a participar del acto de compra y, como lo demuestra Colibrí, en organizar una publicación alrededor de un producto específico.Pero "Marilú" fue la primera muñeca en Argentina que tuvo su propio magazine.

Si bien la muñeca "Marilú" en un principio se publicitó y comercializó a través de Editorial Atlántida fue un emprendimiento de Alicia Larguía. De acuerdo a Daniela Pelegrinelli, Larguía pertenecía a una familia tradicional santafesina, estaba separada y era madre de tres hijos. Para la investigadora, la futura empresaria logró concretar su idea de acompañar una muñeca con una revista gracias a su amistad con Carlos Vigil, en ese entonces director de Billiken. Y para llevar adelante el emprendimiento unió dos tradiciones. Por un lado, se inspiró en La Semaine de Suzette (1905), una revista francesa que regalaba una muñeca llamada Bleuette y publicaba moldes para hacerle ropita. Según la investigadora, $L a$ Semaine...formaba parte de la prensa infantil moralizante destinada a la alta y pequeña burguesía católica francesa. Por otro lado, se nutrió de su conocimiento de las ferias anuales de juguetes que se realizaban en Alemania, desde donde importó "Marilú" hasta que la misma comenzó a producirse localmente en 1940.28

Con estas influencias, Larguía creó una muñeca cuyo nombre era "Marilú". Tal como la representaba la tapa de Billiken que da la bienvenida al año 1933, la marca distintiva de la nueva muñeca era su cuidadosa vestimenta, a la usanza de las niñas de la clase alta y medias acomodadas, su primorosos trajecitos y

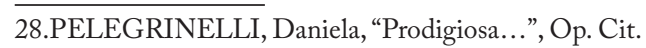

vestidos y sus accesorios de sombrero, cinturón, medias y zapatos haciendo juego. (Imagen I y II) Éstos, acompañados por muebles en miniatura, comenzaron a comercializarse en un sector de la "Librería Atlántida" en Lavalle 720 y luego en un ámbito especializado llamado "La Casa de Marilú", en el nuevo local de la editorial en la calle Florida. E1 éxito empresarial incentivó a Larguía a independizarse de Editorial Atlántida en 1934 -en aquello referente a la comercialización de la muñeca y sus accesorios-, a constituir su propia empresa -Larguía \& Cía- y a erigir, a pocos metros de "Casa Atlántida", la "Casa Marilú”, que no sólo vendió la muñeca, su ajuar y muebles sino también ropa para niñas y con el tiempo para mujeres. ${ }^{29}$ Como señala Susana Sosenski Correa para el caso mexicano, estos espacios -que en ocasiones se acondicionaban especialmente para los niños- son significativos porque muestran la intención de que las niñas participaran del acto de compra y no se quedaran en su casa a esperar un regalo. ${ }^{30}$ En este sentido, la "Casa Marilú” con ropa para madres e hijas funcionó como un lugar compartido donde la función mediadora de la madre se desdibujaba.

... ¿¿Y cuánto cuesta Marilú?... Muy poco, para lo mucho que vale.

Poned diariamente veinte centavitos en la alcancía. Al cabo de un mes, es decir treinta días, ya podréis ser dueñas de una Marilú... ${ }^{31}$

29. No obstante esta separación comercial, la publicación que salió para acompañar la muñeca continuó editándose, hasta 1937, bajo el sello de la familia Vigil y Alicia Larguía siguió siendo su directora.

30. SOSENSKI CORREA, Susana, "E1 niño consumidor...”, Op. Cit., p. 200.

31. “Marilú qué es”, Billiken, Buenos Aires, 12-12-1932. 
"Marilú" costaba inicialmente entre seis $\mathrm{y}$ siete pesos y era un juguete costoso si tenemos en cuenta que se podían comprar muñecas en "Tiendas San Juan" desde dos pesos con cincuenta. ${ }^{32}$ Pero tampoco era la que tenía el precio más elevado del mercado. Por ejemplo, la misma "Tiendas San Juan" contaba con muñecas que superaban los seis pesos. Sin embargo, la diferencia de "Marilú" con sus competidoras eran los accesorios, que estimulaban aún más a la compra y eran más caros que la propia muñeca. Así, un vestido podía oscilar entre los siete y los diez pesos y los muebles entre los cinco y los diez pesos. ${ }^{33}$ De manera que las distinciones de clase estaban dadas por la vestimenta "original" de la muñeca y no por la posesión de la muñeca en sí misma ya que, como veremos más adelante, se podía acceder a una a través de un concurso o donación. En un diálogo imaginario entre la muñeca y su "tía", "Marilú" confesó que tenía un pequeño defecto: era coqueta y le gustaba cambiar de ropa. A lo que "Tía Susana"-alter ego de Alicia Larguía- respondió:

No te preocupes por eso, Marilú. Billiken ha pensado en todo, y además de publicar los moldes para que tu mamita pueda hacerte ella misma tus vestidos, te ha instalado una verdadera "casa de modas" para ti solita. Allí podrá ir tu mamita y comprarte todo lo que necesites en zapatos, medias, carteras, cinturones, sombreros, ropa interior, vestidos, tapados, trajes de baño, piyamas, impermeables... ${ }^{34}$

32. Publicidad “Tiendas San Juan”, Billiken, Buenos Aires, 02-01-1933.

33. "Los muebles de Marilú”, Marilú, Buenos Aires, 11-05-1933; "El ajuar de Marilú”, Marilú, Buenos Aires, 20-09-1934.

34. "Marilú", Billiken, Buenos Aires, 21-11-1932.
Como señala Daniel Cook, el reconocimiento del niño consumidor, como legítimo, individualizado e independiente, es una construcción que tiene raíces profundas en la industria textil. Este fue un proceso se buscó tratar a los niños como "consumidores reales", diseñando ropa de acuerdo a nuevos talles -como bebés, infante, toddler o niño pequeño, niño- y por género, a partir de la creación de otros productos de acuerdo a sus "necesidades" y "deseos" (y las de sus madres), reestructurando y redecorando espacios de consumo. ${ }^{35}$ Sin duda, en una escala pequeña, la muñeca "Marilú", la revista Marilú y finalmente la "Casa Marilú" contribuyeron significativamente en la construcción, y en la representación, de la niña consumidora de los sectores medios y medios acomodados.

\section{Marilú, la mejor amiga de las niñas}

El primer número de Marilú, como una revista independiente de Billiken, apareció el 9 de Marzo de 1933. Al igual que la mayoría de las publicaciones de Editorial Atlántida, tenía un valor de veinte centavos, la presentación era cuidada, y contaba con el formato de magazine para niños inaugurado por Billiken -aunque prácticamente no había otra publicidad que no fuera la propia "Marilú" y su casa. Es muy probable que la tirada de la revista no alcanzara a cubrir los costos de edición pero, de la misma forma que Constancio C. Vigil se refería a otros magazines de la empresa que daban "pérdida", sostenía que no importaba en el negocio global de la compañía porque ella era vehículo de las demás y les servía

35. COOK, Daniel, The Commodification of Childhood..., Op. Cit. 
Imagen 1: Marilú ataviada con vestido fondo blanco con lunares rojos. La boina, el cinturón y los zapatos están haciendo juego en rojos.

Billiken, 02-01-1933.

Fuente: Hemeroteca de la Biblioteca Nacional

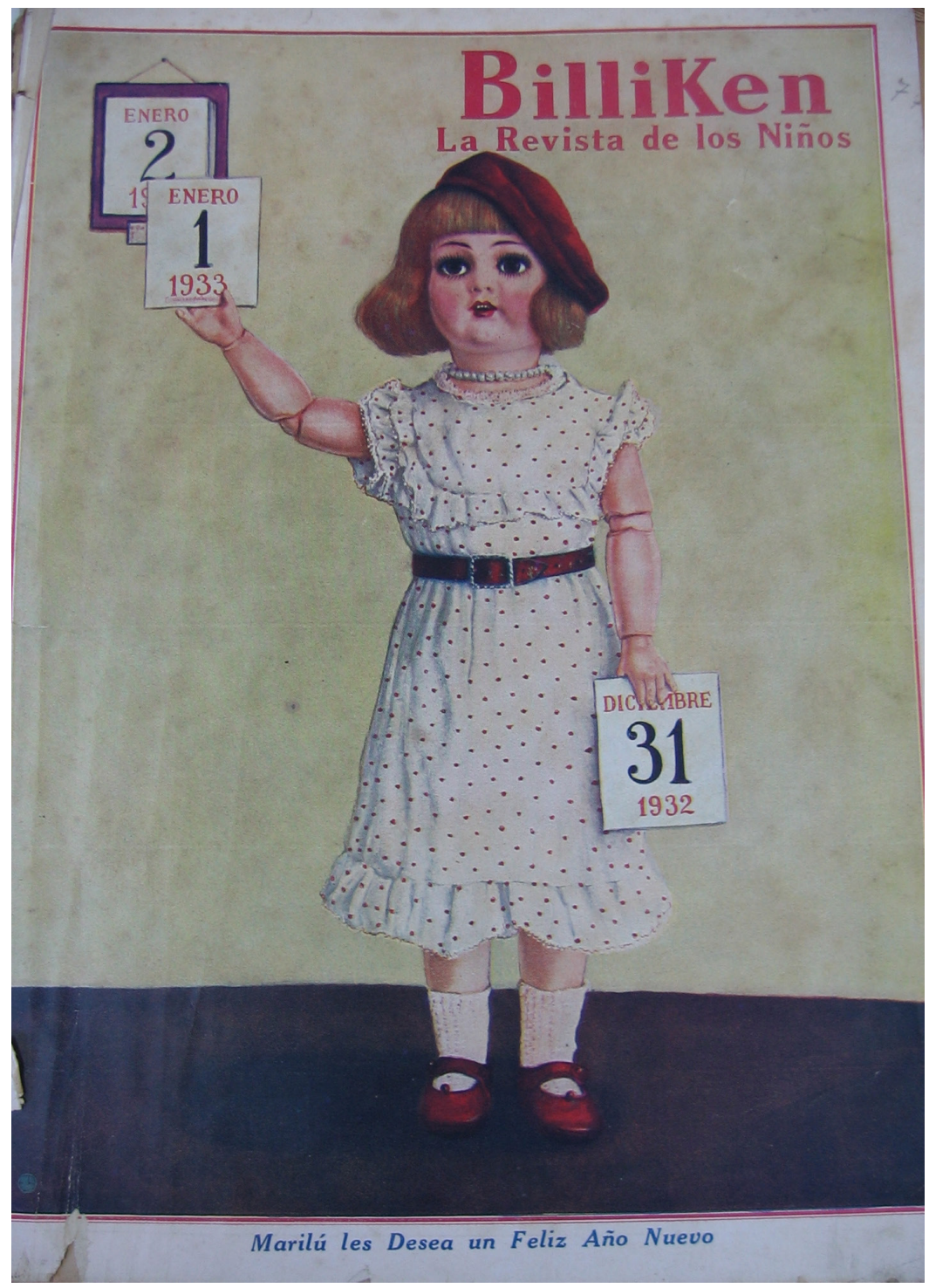




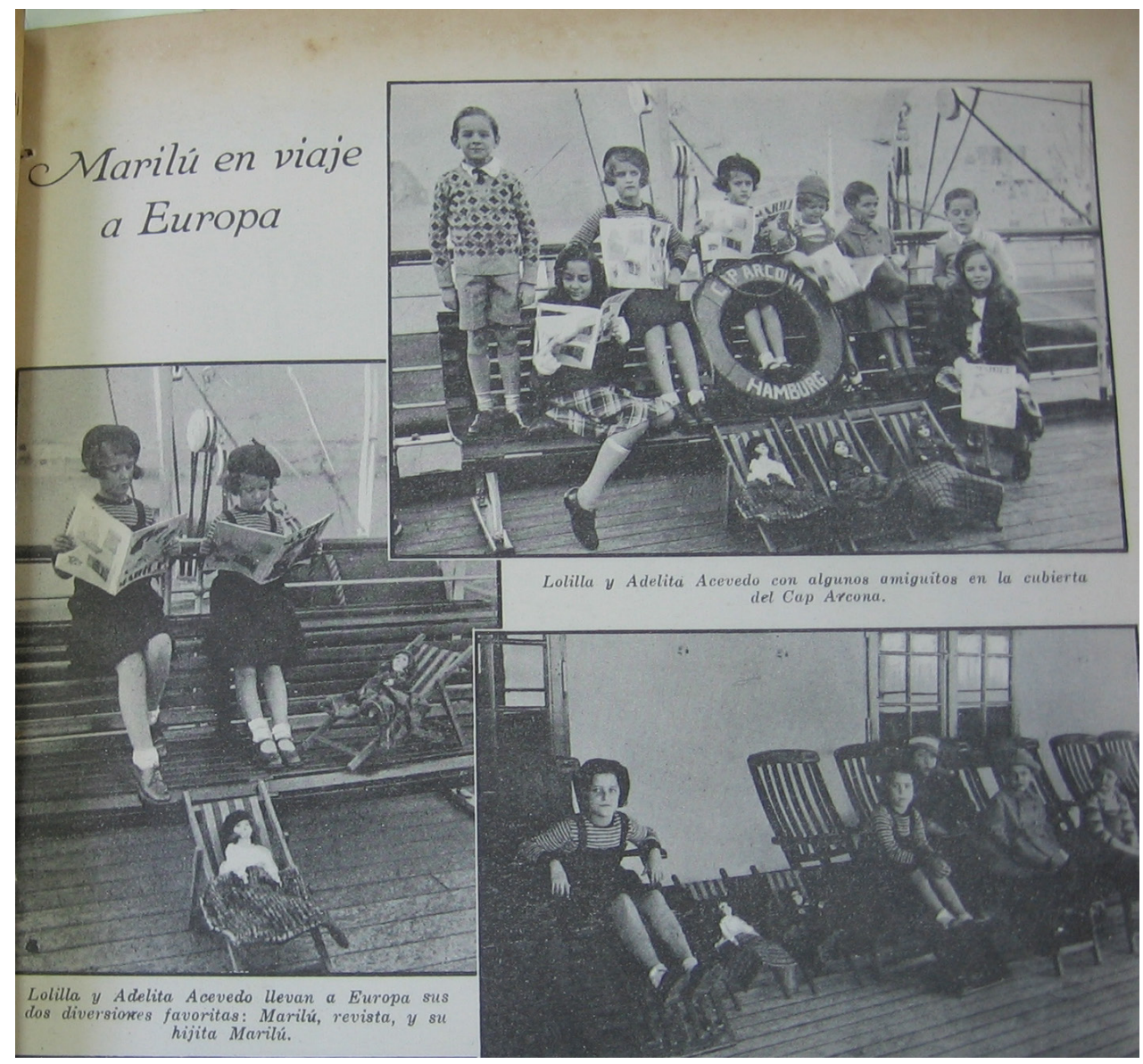

Imagen 2: Niñas de clase alta leen la revista Marilú y llevan a sus muñecas y accesorios a su viaje a Europa. Las chicas y las muñecas llevan un estilo parecido. Especialmente en el corte de cabello, los zapatos y la boina.

Marilú, 6-07-1933

Fuente: Hemeroteca de la Biblioteca Nacional 
de propaganda. ${ }^{36}$ De manera que mantener un número alto de publicaciones $\mathrm{y}$ de varios géneros o destinadas a públicos distintos -en ese momento Editorial Atlántida contaba con nueve revistas en el mercado- tenía una lógica que excedía la ganancia inmediata, o dicho de otra forma, daba otro tipo de réditos -incluso simbólicos-, por lo menos por algún tiempo. Así, Marilú se construyó como una publicación que pretendía promocionar una muñeca al mismo tiempo que una revista que se dirigía exclusivamente a las niñas, toda una novedad en sí misma en el mercado argentino.

La mejor amiga de las niñas, que trataba de cubrir todo el universo infantil femenino, se formulaba sin fisuras de manera que desde las tapas hasta las historietas y algunas publicidades cubría todo aquello que se suponía interesaba a las niñas. Se estructuraba -de acuerdo a un boletín de circulación interna de la empresa y de promoción entre los diversos agentes distribuidores- en secciones de "orientación moral" como los "Consejos de Tía Susana" y el "Correo de Tía Susana"; de "valor práctico" entre los que se encontraban las recetas de cocina y las labores"; "temas intelectuales, artísticos y literarios" en las láminas a color, las novelas y poesías seleccionadas y en "Los domingos de Corita" columna dedicada a la historia; el "arte de escribir" estimulado a través de la correspondencia entre las lectoras; "secciones amenas" con dibujos para colorear, juegos, pasatiempos, historietas, fotografías; y "modas infantiles" "punto preferentemente tratado en Marilu". ${ }^{37}$

36. PEREZ MARILUZ, Enrique, Vigil en su tiempo y en su obra, Mosca Hnos., Montevideo, 1967, pp. 159-160.

37. Boletín Semanal de la Editorial Atlántida S.A, Buenos Aires, 24-04-1934, Año II, No 73.
Toda la propuesta gráfica de Marilú se construyó sobre el supuesto de que las lectoras eran dueñas, admiradoras o aspirantes a tener una "Marilú", o por lo menos a una muñeca que se le pareciera. Esa posesión, mediante su adquisición en el mercado, las convertía en "mamitas" y a las muñecas en "hijitas". $\mathrm{Si}$ eran buenas "mamitas" o no, dependería de la atención y cuidados que prestaran a su "hijita". En este sentido, la revista fue el medio que Larguía encontró para establecer una relación directa con sus pequeñas lectoras y clientas, enseñando cómo usar correctamente el producto. Así señalaba:

Irma Susana Lafleche -Le aconsejo no bañar a su Marilú, pues seguramente se arruinaría. Si la nota sucia puede pasarle por el cuerpo un trapito húmedo y después secarla bien. Ya veo que es una buena mamita que se preocupa mucho por su hijita ${ }^{38}$

A vuestra edad... considerábamos a nuestras [hijas] como a verdaderas criaturas y no debíamos dejarlas nunca, bajo ningún pretexto, como las veo frecuentemente tiradas bajo de un mueble, con el traje manchado... en cuanto a olvidarlas en el jardín o en el balcón, sin pensar en la humedad de la noche... ${ }^{39}$

Más allá de los diversos usos, cuidados, cambios y metamorfosis que en manos de las niñas recibían las muñecas entiendo a las advertencias sobre el consumo de la muñeca no sólo como discursos a partir de los cuales se buscaba vender el producto sino también como síntomas de la construcción de valores positivos

38. "Correo de Tía Susana”, Marilú, Buenos Aires, 2505-1933.

39. “Consejos de Tía Susana. Lo que mis sobrinitas tienen que ser para sus muñecas", Marilú, Buenos Aires, 12/1936. 
alrededor de los juguetes comprados en una juguetería. A partir de las recomendaciones de Larguía, considero que se estaba operando un deslizamiento mediante el cual la adquisición de un juguete en el mercado y el rol de los niños -en este caso las niñas- como consumidores comenzaban a ser legitimados y valorizados por sectores medios que tenían acceso al mercado. Al contrario de Constancio C. Vigil, que supuso un modelo para la infancia que apreciara y valorara más el trabajo manual, la revista para niñas dejó entrever que más se estimaba y cuidaba a la muñeca por su valor en el mercado. ${ }^{40}$ Parafraseando a la creadora del negocio, y como advertí anteriormente, una "Marilú costaba muy poco, para lo mucho que valía". ${ }^{41}$

De esta forma, comenzó a estabilizarse una idea que se venía construyendo, aunque no sin tensiones, en la propia Editorial Atlántida: los niños tenían derecho a los productos de la modernidad como consumidores de bienes y servicios. Además, de que este rol era estimado, les brindaba una autonomía relativa que consistía en elegir, demandar, desear, ahorrar y salir de compras. En este sentido, los "Festivales Billiken" y los "Comités Billiken" habían sido espacios de promoción de bienes y servicios para la infancia, tanto para chicas como para chicos y las páginas de Billiken estaban cargadas de publicidades y no sólo de juguetes y comestibles sino también de golosinas y

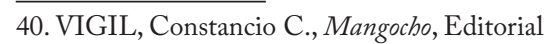
Atlántida, Buenos Aires, 1927, p. 25; VIGIL, Constancio C., "La otra muñeca y la tuya", en Cartas a Gente Menuda, Talleres Gráficos RBP, Buenos Aires, 1927. Ciertas corrientes pedagógicas que revitalizaron este aspecto. $\mathrm{Al}$ respecto consultar: CARLI, Sandra, Niñez, Pedagogía y Politica..., Op. Cit., pp. 199-207.

41. "Marilú qué es”, en Billiken, Buenos Aires, 12-121932. entretenimientos. ${ }^{42}$ Con la asociación entre la muñeca "Marilú" y la revista Marilú, la identificación de las niñas como consumidoras no dejó lugar a equívocos.

\section{Marilú y "Marilú" salen a ganar el mercado}

Algunas estrategias empleadas por Billiken para posicionarse en el mercado y hacerse conocida en sus comienzos fueron recreadas por la revista para niñas. Entre ellas, el diálogo de la directora con las lectoras y los correos entre lectoras. De esta forma funcionó el "Club de Sobrinas de Tía Susana”(S.D.T.S.) pensado para que las "primitas" pudiesen intercambiar correspondencia, figuritas y moldes de ropa para la muñeca. En una instancia fundacional estas secciones apuntaron a consolidar un público lector y rellenar páginas. Pero sobre todo, como otras publicidades, tendían a enseñar a identificar e instalar definitivamente la muñeca, a desear y demandar un producto específico y, al mismo tiempo, crear fidelidad a través de la conformación de una comunidad de lectoras -consumidoras de la muñeca y sus accesorios. ${ }^{43}$ Con este objetivo, la campaña de publicidad y promoción desarrollada por Larguía fue intensa y agresiva al organizar en

42. Los "Festivales Billiken" (1920-1923) consistían en una jornada al aire libre donde se desarrollaban diversos espectáculos para los niños, varios de los cuales promocionaban los servicios en las páginas del semanario. Por su parte, los “Comité Billiken” (1920-1926) eran asociaciones de niños y niñas -de entre ocho y dieciséis años- que llevaban adelante acciones filantrópicas y de caridad. Se desarrollaron bajo el amparo de Billiken pero no "pertenecían" a Editorial Atlántida.

43. SOSENSKI CORREA, Susana, "E1 niño consumidor...”, Op. Cit., p. 204; MINZI, Viviana, “Los chicos según la publicidad...”, Op. Cit. 
la Capital Federal las exposiciones o "Ferias Marilú" en las cuales se concedían premios a las muñecas mejor ataviadas. ${ }^{44}$ También, reeditando una estrategia que Billiken había utilizado en sus comienzos, organizó "festivales" que combinaban la exposición de la muñeca y espectáculos para los chicos. Éstos, centrados en las niñas, no se circunscribieron a la Capital Federal y se desarrollaron en algunas ciudades del interior del país, entre ellas Santa Fe y Paraná. ${ }^{45}$

En el intento de imponer el producto, y aprovechando la temporada estival, "Marilú" y Marilú realizaron un concurso de trajes en la recién inaugurada Exposición-Feria de Mar del Plata. ${ }^{46}$ Pero si en las exposiciones-concursos organizados por Billiken, por ejemplo el de las "Cien Muñecas", la dueña de la muñeca mejor ataviada se llevaba premios simbólicos, como medallas, en la edición de Mar del Plata, las niñas, por un lado, no disponían de total libertad para confeccionar el traje que quisieran -ya que éstos estaban pautados: de "sport", calle o fiesta-; $y$ por otro lado, ganaban objetos tan deseados como la propia "Marilú". Así, la mejor vestimenta de "sport" o playa obtenía un juego de "muebles Marilú", la segunda un "baúl Marilú" y la tercera un juego de muebles de caño; el primer premio de ropa "de calle" era una glorieta, el segundo un "baúl Marilú" y el tercero una "hamaca Marilú"; y el primer premio para el vestido "de fiesta" consistía en un "ajuar Marilú", el segundo un toilette con el

44. Boletín Semanal de la Editorial Atlántida S.A., Buenos Aires, 17-10-1933, Año I, No 46.

45. Boletin Semanal de la Editorial Atlántida S.A., Año I, No 52, 28-11-1933; Boletín Semanal de la Editorial Atlántida S.A, Año II, No 57, 02-01-1934.

46. Boletin Semanal de la Editorial Atlántida S.A., Buenos Aires, 30-01-1934, Año II, No 61. juego completo y el tercero un toilette básico. Es decir que la mayoría de los premios eran los accesorios de la muñeca.

También Marilú reeditó los sorteos que supo hacer Billiken donde el juego no debería estar completamente librado al azar sino condicionado por un estímulo moralizante.Para participar, las maestras -de la Capital Federal, del interior del país e incluso del exteriorenviaban a la editorial el nombre, apellido y domicilio de las niñas que ellas considerasen las más estudiosas del grado. La nota debía ser acompañada con el nombre de la maestra, el grado que dirigía y los datos de la escuela. Sólo esas niñas "señaladas" tendrían derecho al sorteo que se realizaba semanalmente en la empresa. Para hacer transparente el juego se invitaba a las niñas, todos los jueves a las cuatro de la tarde, a presenciar la extracción de la "célula". ${ }^{47}$ A diferencia del "Concurso de las Cien Muñecas" donde los juguetes circulaban de mano en mano, "Marilú" no era para todas las niñas. Estaba destinada para las que pudiesen comprarla y para las mejores alumnas tocadas por la suerte. En fin, aquellas que lo merecieran. Estas ideas también se representaban en las ficciones.

El cuento "Cuatro niñas y una muñeca" narra la historia de Teresa y Lucila que, dueñas de una "Marilú", jugaban en la Recoleta con el juguete. Pero en un momento de descuido, Mariquita, que era "muy pobre", y tenía una "muñeca horrorosa, de cartón, toda rota y desteñida", creyó "encontrar" una "Marilú" y decidió llevársela a su hermana. Rosa, al comprender que esa muñeca "no se había perdido" resolvió devolverla. Como reconocimiento a la

47. Boletin Semanal de la Editorial Atlántida S.A., Buenos Aires, 17-07-1934, Año II, No 85. 
honradez de Rosa, las niñas ricas compraron una "Marilú" para Mariquita, la enviaron a la casa "miserable" y en los "suburbios", donde vivían las hermanas, con una nota que decía "Con la condición que Mariquita no guarde nunca un objeto encontrado". 48

Partiendo de la idea de que los juguetes, en este caso una "Marilú", son una producción cultural que transmite valores socioculturales y reproduce diferencias de género, clase y raza, esta narración es interesante porque parece condensar varias de éstas dimensiones que se proyectarán en toda la revista a lo largo de su permanencia en el mercado. ${ }^{49}$ En primer lugar, divide a las poseedoras legítimas de la muñeca, que vivían en Recoleta y podían comprar el juguete, de otras que eran "merecedoras" de una "Marilú" gracias a su desempeño escolar, sus buenos actos u honradez -por supuesto, sin resentimiento de clase- replicando un modelo que había aparecido en Billiken. Sin embargo, este tipo de narraciones no sólo tiene una acción moralizante sobre el beneficiado sino también sobre el benefactor, siendo la caridad un valor y una práctica deseable. ${ }^{50}$ En segundo lugar, coloca a "Marilú" como una encarnación de distinción y, mientras alecciona a las dueñas de la muñeca, comprada en el mercado, a valorizar a la misma y no dejarla "abandonada", a las que no la tienen las invita a desearla. Al mismo tiempo, mientras que "enseña a consumir jugando" delimita simbólicamente lugares de

48. “Cuatro niñas y una muñeca”, Marilú, Buenos Aires, 06-07-1933.

49. SOSENSKI, Susana, "Producciones culturales...", Op. Cit.

50. BRAFMAN, Clara, "Billiken. Poder y consenso en la educación argentina (1919-1930), en Todo es Historia, Buenos Aires, 1992, Año XXV, No 298.

122 circulación de la muñeca, contextualiza los usos y adjudica sentidos.

\section{Marilú enseña a las chicas a ser la mujer ideal}

Diseñar una revista moderna, atractiva y tan específica respecto al género y a las edades de las lectoras -ya que las que aparecen "jugando" con la muñeca aparentan tener entre 8 u 11 años pero las que participaban en el correo de lectoras declaraban tener entre 11 y 14 añosno era tarea sencilla, ni siquiera para Editorial Atlántida, una empresa que contaba con una amplia experiencia en la edición de revistas en general y en publicaciones para la infancia en particular. ${ }^{51} \mathrm{El}$ proyecto no era fácil porque, además, implicaba plantear una propuesta diferente a Billiken y distinta a Para Ti (1922), la revista destinada a mujeres de la cual Alicia Larguía también fue directora desde 1933. Asimismo, buscaba captar a las niñas al mismo tiempo que lograr ser aceptada por los padres, de manera que cada material que aparecía en las páginas era presentado como "especial y escrupulosamente seleccionado". La revista pretendía transformarse en una aliada de la madres ya que se definía a sí misma como un

...elemento indispensable en todos los hogares donde se aspira a realzar en las hijas la mujer ideal: aquellas que, junto con las dotes espirituales que la convierten en una agradable compañera de todos los momentos, reúne los conocimientos prácticos que la transforman en el hada de la casa. ${ }^{52}$

51. BONTEMPO, María Paula, "Editorial Atlántida. Un continente de publicaciones, 1918-1936”, Tesis de Doctorado, Universidad de San Andrés, 2013.

52. Billiken, Buenos Aires, 06-03-1933. 
La fórmula que implementó fue hacer girar el semanario alrededor de la muñeca -que finalmente proyectaba y entrenaba en la futura maternidad-, la educación doméstica y una dosis de religiosidad más intensa que en otras publicaciones de la misma empresa. Examinemos estos aspectos. En sintonía con aquellos sectores que querían mostrarse "respetables", el hogar funcionó como un eje articulador de la publicación..$^{53}$ Marilú se proponía como una alternativa a las actividades en el espacio público y, como celebraba la directora en el número inaugural, "mucho más nos vamos a divertir en casa (en lugar de ir al teatro) con nuestras preciosas revistas". ${ }^{54}$ Esta intención se reforzó con las portadas, la mayoría y sobre todo en los primeros tiempos, a cargo de pintora tucumana María Mercedes Rodrigué de Soto Acebal (1891-1980), acuarelas que representaban a las niñas o a sus muñecas leyendo, tocando el piano, cocinando o cosiendo, pero también, y quizás pensando en los diferentes usos que harían las niñas de las muñecas, representaba a las "Marilú" como aviadoras, ciclistas y vendedoras, generando pequeñas fisuras en el discurso "puertas adentro" ${ }^{55}$ Finalmente, la maternidad constituyó el núcleo y razón de ser de la comunidad de lectoras ya que preferentemente,

53. MÍGUEZ, Eduardo, "Familias de clase media: la formación de un modelo", en DEVOTO, Fernando, MADERO, Marta (directores) Historia de la Vida Privada..., Op. Cit.; BARRANCOS, Dora, "Moral sexual, sexualidad y mujeres trabajadoras en el período de entreguerras", en DEVOTO, Fernando, MADERO, Marta (directores) Historia de la Vida Privada en Argentina. La Argentina entre multitudes y soledades. De los años treinta a la actualidad, T. III, Taurus, Buenos Aires, 1992, pp. 199-225.

\section{Marilú, Buenos Aires, No 1, 9-3-1933, p. 12.}

55. Reconocida artista de la época. Para más referencias ver: SOSA DE NEWTON, Lily, Diccionario Biográfico de Mujeres Argentinas, Plus Ultra, Buenos Aires, 1986. como hemos visto con anterioridad, cada niña era una "mamita de una 'Marilú".

El discurso referido al rol femenino en la revista no es novedoso y da cuenta de la maternalización de las mujeres y de la necesaria "educación maternal" que diversos discursos e instituciones venían realizando desde comienzos del siglo veinte. ${ }^{56} \mathrm{Si}$ a las mujeres se les enseñó el oficio de madres a través de los consejos brindados por médicos, puericultoras y diversas instituciones de la salud, a las niñas se les inculcaba el ideal doméstico de feminidad en las asignaturas escolares de Labores y Economía Doméstica ${ }^{57}$ y se cuidaba su cuerpo reproductor en las clases de Educación Física. ${ }^{58}$ Marilú formó parte de esta corriente y reforzó, desde el mercado editorial y desde la industria del juguete, la educación en la maternidad. (Imagen III)

En cuanto a las "dotes espirituales" que Marilú proponía eran congruentes, sin dudas, con una educación católica. La revista comenzó a editarse en un momento de conservadurismo político y de renacimiento religioso que, desde diversos ámbitos, incluso el educativo, pretendió "recristianizar" la sociedad y la infancia. Además, sus páginas se editaron durante el fervor católico que se manifestó

56. NARI, Marcela, Politicas de Maternidad y Maternalismo Politico. Buenos Aires, 1890-1940, Editorial Biblos, Buenos Aires, 2004.

57. LIONETTI, Lucía, La Misión Política de la Escuela Pública. Formar a los Ciudadanos de la República (18701916, Miño y Dávila, Buenos Aires, 2007.

58. SCHARAGRODSKY, Pablo, "El padre de la Educación física argentina: fabricando una política corporal generizada (1901-1938)", en AISENSTEIN, Ángela, SCHARAGRODSKY, Pablo Tras las Huellas de la Educación Física Escolar Argentina. Cuerpo, Género y Pedagogía, 1880-1950, Prometeo Libros, Buenos Aires, 2006. 
Imagen 3: Portada de Marilú realizada por María Mercedes Rodrigué de Soto Acebal. Marilú, 16-11-1933

Fuente: Hemeroteca de la Biblioteca Nacional

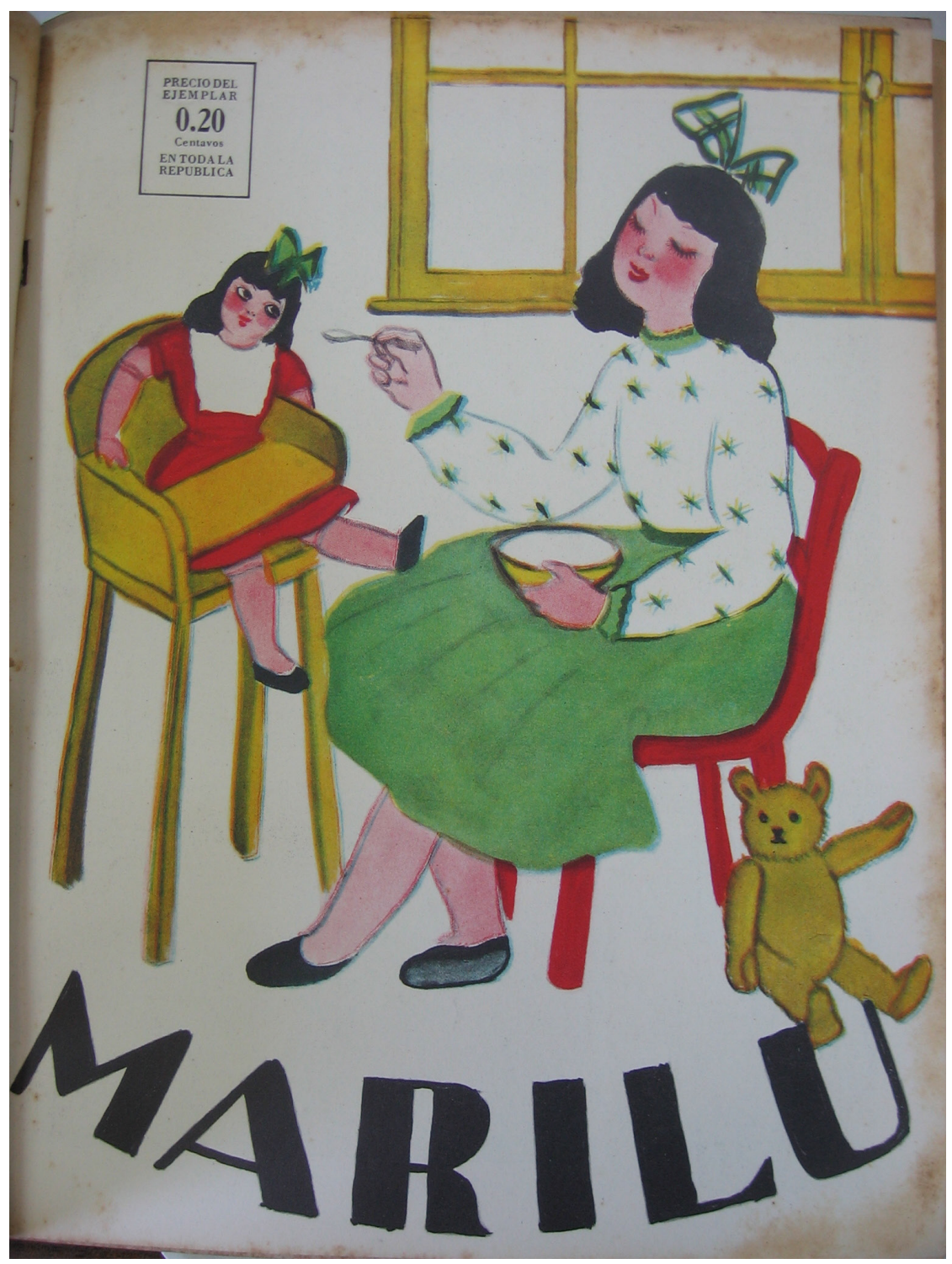


con mayor intensidad en el Congreso Eucarístico de 1934, fecha en la cual Marilú -al igual que Para Ti y Atlántida- dedicó espacio al acontecimiento e incluso presentó modelos de ropa especiales para la muñeca. ${ }^{59}$ Con el seudónimo de "Tía Susana”, Larguía no sólo aconsejaba ir a misa y la "abuelita" -sección a cargo de Agustina García Mansilla de Mantilla- relataba y explicaba diversos pasajes de los evangelios, sino también que aparecieron referencias a los sacramentos en diferentes géneros literarios y se reprodujeron cuadros con motivos religiosos. El modelo de espiritualidad divulgado por Marilú -que no era orgánico de la Iglesia Católica- es el que, quizás, se esperaba de las niñas católicas: regulado bajo la vigilancia materna -en este caso de Tía Susana- institucionalizado, piadoso, devoto y "respetable", de acuerdo a un conjunto de prácticas y comportamientos que las distinguía y que la revista estimulaba. ${ }^{60}$

Sin embargo, la opción del catolicismo en las páginas de la revista es llamativa ya que si bien los escritos de Constancio C. Vigil, y de la editorial en general, eran de orientación cristiana, estaban destinados a públicos amplios y no circunscriptos a una confesión. Aquí, como sugiere Matthew Scheneirov para el análisis de revistas, no descuido la ideología católica y cristiana de los editores y la directora, pero considero que la opción abierta por el catolicismo se debió, principalmente,

59. DI STEFANO, Roberto, ZANATTA, Loris, Historia de la Iglesia Argentina. Desde la Conquista hasta fines del siglo XX, Grijalbo/Mondadori, Buenos Aires, 2000.

60. ACHA, Omar, "Catolicismo social y feminidad en la década de 1930: de Damas a Mujeres", en ACHA, Omar, HALPERIN, Paula (compiladores) Género, Cuerpo e Identidades. Estudios de Historia de Género en Argentina, Ediciones del Signo, Buenos Aires, 2000. a una estrategia comercial. ${ }^{61}$ Por un lado, esta filiación religiosa era necesaria para sostenerse en el mercado o, por lo menos, no ser rechazada. En caso de que realmente fuese cierto que una publicación editada bajo el sello de Editorial Atlántida constituía una "garantía moral”, según se promocionaban a sí mismos, una revista para niñas -en cuyos cuerpos recaía la "moral" y "decencia" de la familianecesitaba seguros extras. ${ }^{62}$ Como señalé, diseñar una revista para niñas era difícil y la orientación abiertamente católica garantizaba la moral de los contenidos publicados. Por otro lado, la identificación católica le permitía a la "Casa Marilú" vender productos asociados con la religión. Si la muñeca contó con trajes especiales para el Congreso Eucarístico también los tenía para la Primera Comunión -con reclinatorios incluidos.

Estimo que los contenidos de Marilú y parte del consumo que estimulaba a través de la muñeca, sus accesorios, la ropa para niñas y los concursos construían mensajes que entraban en fricción a pesar del intento de crear una publicación sin fisuras. Por un lado, se aleccionaba a las niñas a permanecer en el hogar, bajo la estricta mirada de "Tía Susana" y de la "abuelita". Por otro lado, se las alentaba a salir y hacerse visibles y a experimentar cierta autonomía en el acto de consumir. ${ }^{63}$ En

61. SCHENEIROV, Matthew, The Dream of a New Social Order. Popular Magazines in America, 1893-1914, Columbia University Press, New York, 1994.

62. PEREZ MARILUZ, Enrique, Vigil en su tiempo..., Op. Cit., pp. 157-160.

63. Diez años antes, Para Ti había realizado una operación similar en su construcción de la "mujer moderna". Al respecto véase BONTEMPO, María Paula, "Para Ti: una revista moderna para una mujer moderna, 1922-1935" en Estudios Sociales, Santa Fe, 2011, Universidad Nacional del Litoral, 2011, No 41, pp. 127-146. 
este punto, el discurso monolítico, estricto y moralizante de la revista, que coincidía con el católico, encontraba una pequeña fisura. Si bien los fieles católicos participaban de la cultura de masas y del consumo a través de las prácticas religiosas, ${ }^{64}$ los discursos orgánicos eran reticentes al consumo de los llamados "afeites femeninos" ya que estos eran contrarios a la "belleza natural" y "auténtica" como sostenía, por ejemplo, Criterio. ${ }^{65}$ La propia “Tía Susana" advertía sobre este "pequeño defecto" y señalaba a sus lectoras que cuando fuesen a misa, por más elegantes que estuvieran, no debían pensar "sólo en cosas frívolas" 66 y que la verdadera "belleza es sencilla y natural". ${ }^{67} \mathrm{Sin}$ embargo, casi al mismo tiempo, la publicación sacaba colecciones de vestidos para niñas para la temporada invernal, daba lecciones de cómo vestir bien, y enseñaba qué modelos de cortes y melenas se usaban. ${ }^{68}$

64. LIDA, Miranda, MAURO, Diego (coordinadores) Catolicismo y sociedad de masas en Argentina: 1900-1950, Prohistoria, Rosario, 2009.

65. ACHA, Omar, "Organicemos la contrarrevolución: discursos católicos sobre géneros, la familia y la reproducción a través de Criterio (1928-1943)", en ACHA, Omar, HALPERÍN, Paula (compiladores) Género, Cuerpo..., Op .Cit.

66. “Consejos de Tía Susana: En la Iglesia”, Marilú, Buenos Aires, 12-10-1933.

67. "Consejos de Tía Susana: Coquetería mal entendida", Marilú, Buenos Aires, 26-07-1934. En las ficciones también se trataba el tema, por ejemplo en "La coqueta engreída”, Marílú, Buenos Aires, 26-07-1934.

68. “Cabellos Semilargos”, Marilú, Buenos Aires, 3003-1933; Marilú, Número Extraordinario, Buenos Aires,1936; Marilú, Buenos Aires, 03-1936; Marilú, 05/1936; Marilú, Buenos Aires, 06-1936

\section{Consideraciones finales: el éxito de una muñeca}

"Marilú" apareció en el mercado en el marco de la conformación de una cultura de la infancia que estaba siendo construida por una trama se sensibilidades donde confluían diversas instituciones, discursos, agentes y representaciones. Entre ellas se analizó la revista Billiken, un producto cultural de Editorial Atlántida de gran difusión en las familias y en la escuela, como un espacio fundacional y fundamental para la difusión y legitimación de los juguetes, en especial de las muñecas, en tanto artefactos constitutivos del mundo infantil. Aquí también hizo su presentación en sociedad "Marilú".

Para lograr captar el mercado, la creadora de la muñeca - Alicia Larguía- y Editorial Atlántida -empresa que vehiculizó la publicidad y comercialización de la muñeca y sus accesorios en los primeros tiempos- desarrollaron una serie de estrategias que consistieron en la organización de concursos, la celebración de ferias y festivales no sólo en la ciudad de Buenos Aires sino también en varias ciudades del interior, y fundamentalmente, en el diseño de una revista: Marilú, la mejor amiga de las niñas. Con la experiencia de la empresa en la edición de revistas y con el modelo de Billiken como magazine infantil, se creó Marilú cuyo propósito era el de publicitar la muñeca, sus accesorios y las actividades que se disponían alrededor de ella, al mismo tiempo que formar y consolidar una comunidad de lectorasconsumidoras de la muñeca y la revista. Para las que tenían una "Marilú", Marilú fue una guía de consumo, es decir de cómo usar el juguete, y para las que no, constituía un manual de cómo 
manipular otras muñecas mientras esperaban llegar a comprar o poseer, quizás a través de un regalo, una donación o el azar, una "verdadera Marilú". Para ambas, el magazine fue un manual del deber ser femenino de la primera mitad del siglo veinte, donde la domesticidad convivía con los deseos de consumo y con los valores y preceptos espirituales identificados con los católicos. Si bien considero que esta identificación religiosa constituyó una estrategia para ser aceptada en el mercado -ya que "garantizaba" ciertos contenidos- fue, simultáneamente, una limitación para acceder a públicos más amplios.

Porque la publicación era, también, un objeto de consumo en sí mismo que pretendía mantenerse en el mercado. En este sentido, Marilú, como he señalado, organizó concursos, se esforzó por incentivar suscripciones, buscó una mayor participación de las lectoras, intentó crear la "Liga Infantil Marilú" ${ }^{9}$, cambió de formato varias veces, incluyó mayor cantidad de material, abarató su costo a diez centavos, incentivó los "Marilú Clubs" -un programa de actividades para que las niñas realizaran los domingos junto con amigas- y sumó audiciones de radio -espacio que también tenían otras publicaciones infantiles como Billiken y Figuritas (1936). ${ }^{70}$ Finalmente, en 1937, se transformó en una revista de moda para mujeres y apareció sólo esporádicamente.

69. "Liga Infantil Marilú”, Marilú, Buenos Aires, 1209-1935; "Liga Infantil Marilú”, Marilú, Buenos Aires, 19-12-1935.

70. Tía Susana se comunicaba con sus lectoras a través de Radio Municipal los martes y viernes a las 15.30. Marilú, Buenos Aires, 16-01-1937. Billiken dedicaba audiciones a sus lectores los sábados de 12 a 12.30 por Radio Ultra. Billiken, Buenos Aires, 11-01-1937. Y Figuritas, muy irregularmente debido a "las exigencias deportivas" los domingos. Figuritas, Buenos Aires,15-10-1937.
Es probable que la acotada repercusión de la revista Marilú -si la comparamos con otros productos de Editorial Atlántida que permanecieron en el mercado por décadasse deba a las limitaciones intrínsecas de la publicación. Por un lado, como indiqué, se limitaba a un público exclusivo y de una confesión religiosa. Por otro lado, frente a publicaciones más inclusivas, que incorporaban varios modelos de niñez, donde las publicidades no se circunscribían a algunos comercios lujosos o que contaban con mucho más material para la escuela, como Billiken y en cierta medida también como Figuritas, Marilú tenía poco que ofrecer. Finalmente, si uno de los objetivos más importantes de la revista era publicitar la muñeca "Marilú", cuando éste fue cumplido ya no había muchas razones para mantener una publicación semanal. Mientras que el modelo de revista no tuvo el éxito suficiente como para mantenerse en los quioscos de revistas por más tiempo, la muñeca "Marilú" logró instalarse como un modelo estético que fue continuado y renovado por otras. ${ }^{71}$

Con la aparición de la muñeca y la revista se afianzó una idea que se desarrollaría más tarde: era legítimo que los niños aspirasen a juguetes del mercado. En este sentido, considero que el análisis histórico de las primeras décadas del siglo veinte en el marco de la conformación de una cultura de la infancia -que será objeto de futuras investigaciones- repone el panorama de un proceso complejo en la construcción del niño consumidor. En sintonía con esta propuesta, estimo que el análisis de "Marilú" y Marilú contribuye a la construcción,

71. PELEGRINELLI, Daniela, Diccionario de Juguetes Argentinos..., Op. Cit. 
identificación y legitimación de esta dimensión de la infancia. Así, la niña Nelcy había deseado tener una "Marilú" aunque nunca hubiese leído a la mejor amiga de las niñas.

$\sim \ddot{\theta} \sim$

Recibido: 27-05-2015

Aceptado: 01-09-2015

Publicado: 21-12-2015 


\section{Bibliografía}

ACHA, Omar, "Organicemos la contrarrevolución: discursos católicos sobre géneros, la familia y la reproducción a través de Criterio (1928-1943)", en ACHA, Omar, HALPERIN, Paula (compiladores) Género, Cuerpo e Identidades. Estudios de Historia de Género en Argentina, Ediciones del Signo, Buenos Aires, 2000, pp. 105-135.

ACHA, Omar, "Catolicismo social y feminidad en la década de 1930: de Damas a Mujeres", en ACHA, Omar, HALPERIN, Paula (compiladores) Género, Cuerpo e Identidades. Estudios de Historia de Género en Argentina, Ediciones del Signo, Buenos Aires, 2000, pp. 136-195.

ARIÈS, Philippe, El niño y la vida familiar en el Antiguo Régimen, Taurus, Madrid, 1987 (1960).

BARRANCOS, Dora, "Moral sexual, sexualidad y mujeres trabajadoras en el período de entreguerras", en DEVOTO, Fernando, MADERO, Marta (directores) Historia de la Vida Privada en Argentina. La Argentina entre multitudes y soledades. De los años treinta a la actualidad, T. III, Taurus, Buenos Aires, 1992, pp. 199-225.

BENJAMIN, Walter, Reflexiones sobre niños, juguetes, libros infantiles, jóvenes y educación, Nueva Visión, Buenos Aires, 1974 (1928).

BONTEMPO, María Paula, "Para Ti: una revista moderna para una mujer moderna, 1922-1935" en Estudios Sociales, Santa Fe, 2011, Universidad Nacional del Litoral, 2011, No 41, pp. 127-146.

BONTEMPO, María Paula, "Los niños de Billiken. Las infancias en Buenos Aires en las primeras décadas del siglo XX", en Anuario del Centro de Estudios Históricos "Prof. Carlos S. A. Segreti, Córdoba, 2012, año 12 , No 12 , pp. 205-221.

BONTEMPO, María Paula, "Editorial Atlántida. Un continente de publicaciones, 1918-1936", Tesis de Doctorado, Universidad de San Andrés, 2013.

BRAFMAN, Clara, “Billiken. Poder y consenso en la educación argentina (1919-1930), en Todo es Historia, Buenos Aires, 1992, Año XXV, No 298, pp. 70-88.

CARLI, Sandra, Niñez, Pedagogía y Politica. Transformaciones de los Discursos acerca de la Infancia en la Historia de la Educación Argentina entre 1880 y 1955, Miño y Dávila, Buenos Aires, 2005.

CARLI, Sandra, "Los únicos privilegiados son los niños”, en Todo es Historia, Buenos Aires, 2005, V. 457 pp. 58-65.

CARLI, Sandra, "El campo de estudios sobre la infancia en las fronteras de las disciplinas. Notas para su caracterización e hipótesis sobre sus desafíos" en COSSE, Isabella, LLOBET, Valeria, VILLALTA, 
Carla, ZAPIOLA, María Carolina (editoras) Infancias: politicas y saberes en Argentina y Brasil: siglos XIX yXX, Teseo, Buenos Aires, 2011, pp. 31-55.

CIAFARDO, Eduardo, Los niños en la ciudad de Buenos Aires (1890-1910), Buenos Aires, CEAL, 1992.

COOK, Daniel, The Commodification of Childhood. The Children's Clothing Industry and the Rise of the Child Consumer, Duke University Press, Durham, 2004.

COSSE, Isabella, Estigmas de nacimiento. Peronismo y orden familiar. 1946-1955, FCE-UdeSa, Buenos Aires, 2006.

DI STEFANO, Roberto, ZANATTA, Loris, Historia de la Iglesia Argentina. Desde la Conquista hasta fines del siglo XX, Grijalbo/Mondadori, Buenos Aires, 2000.

ELENA, Eduardo, Dignifying Argentina. Peronism, Citizenship and Mass Consumption, University of Pittsburgh Press, Pittsburgh, 2011.

JACOBSON, Lisa, Raising Consumers. Children and the American Mass Market in the Early Twentieth Century, Columbia University Press, New York, 2004.

LIDA, Miranda, MAURO, Diego (coordinadores) Catolicismo y sociedad de masas en Argentina: 1900-1950, Prohistoria, Rosario, 2009.

LIONETTI, Lucía, La Misión Politica de la Escuela Pública. Formar a los Ciudadanos de la República (18701916, Miño y Dávila, Buenos Aires, 2007.

LIONETTI, Lucía, MíGUEZ, Daniel "Aproximaciones iniciales a la infancia”, en LIONETTI, Lucía, MÍGUEZ, Daniel (compiladores) Las infancias en la historia argentina. Intersecciones entre prácticas, discursos e instituciones (1890-1960), Prohistoria, Rosario, 2010, pp. 9-32.

MAYNES, Mary Jo, "Culturas de clase e imágenes de la vida familiar correcta", en KERTZER, David I., BARBAGLI, Marzio, Historia de la Familia Europea. La Vida Familiar desde la Revolución Francesa hasta la Primera Guerra Mundial (1789-1913), V. II, Paidós, Barcelona, 2002.

MÍGUEZ, Eduardo, "Familias de clase media: la formación de un modelo", en DEVOTO, Fernando, MADERO, Marta (directores) Historia de la vida privada en Argentina. La Argentina plural (18701930), T. II, Taurus, Buenos Aires, 1992.

MILANESIO, Natalia, Cuando los trabajadores salieron de compras. Nuevos consumidores, publicidad y cambio cultural durante el peronismo, Siglo XXI, Buenos Aires, 2014.

MINZI, Viviana, "Los chicos según la publicidad. Representaciones de infancia en el discurso del mercado de productos para niños", en CARLI, Sandra, La cuestión de la infancia. Entre la escuela, la calle y el shopping, Paidós, Buenos Aires, 2009, pp. 209-240. 
NARI, Marcela, Politicas de Maternidad y Maternalismo Politico. Buenos Aires, 1890-1940, Editorial Biblos, Buenos Aires, 2004.

PELEGRINELLI, Daniela, "Prodigiosa Marilú", en A boca de sapo. Revista de arte, literatura y pensamiento, Tercera Época, Pilar, 2011, Año XII, No 9, pp. 14-19.

PELEGRINELLI, Daniela, Diccionario de Juguetes Argentinos. Infancia, Industria y Educación 1880-1965, El juguete Ilustrado Editor, Buenos Aires, 2010, pp.15-20, 182-187.

POLLOCK, Linda, "Las relaciones paternofiliales", en KERTZER, David I., BARBAGLI, Marzio, Historia de la Familia Europea. La Vida Familiar a Principios de la Era Moderna (1500-1789), V. I Paidós, Barcelona, 2001, pp. 291-331.

ROCCHI, Fernando, "Inventando la soberanía del consumidor: publicidad, privacidad y revolución del mercado en Argentina, 1860-1940”, en DEVOTO, Fernando, MADERO, Marta (directores) Historia de la vida privada en Argentina. La Argentina plural (1870-1930), T. II, Taurus, Buenos Aires, 1992, pp. 301-321.

ROCCHI, Fernando, "Consumir es un placer: la industria y la expansión de la demanda en Buenos Aires a la vuelta del siglo pasado”, en Desarrollo Económico, Buenos Aires, 1998, V. 37, No 148, pp. 553-558.

RUSTOYBURU, Cecilia, "Jugando a la mamá en los tiempos de la revolución sexual. Los consejos psi sobre juegos y juguetes en los años 1960”, en LIONETTI, Lucía, MíGUEZ, Daniel (compiladores) Las infancias en la bistoria..., Op. Cit., pp. 216-236.

SCHARAGRODSKY, Pablo, "El padre de la Educación física argentina: fabricando una política corporal generizada (1901-1938)”, en AISENSTEIN, Ángela, SCHARAGRODSKY, Pablo Tras las Huellas de la Educación Física Escolar Argentina. Cuerpo, Género y Pedagogía, 1880-1950, Prometeo Libros, Buenos Aires, 2006.

SCHENEIROV, Matthew, The Dream of a New Social Order. Popular Magazines in America, 1893-1914, Columbia University Press, New York, 1994.

SOSA DE NEWTON, Lily, Diccionario Biográfico de Mujeres Argentinas, Plus Ultra, Buenos Aires, 1986.

SOSENSKI CORREA, Susana, "El niño consumidor: una construcción publicitaria de mediados de siglo XX”, en ACEVEDO, Ariadna, LÓPEZ CABALLERO Paula (coordinadores) Ciudadanos inesperados. Procesos de formación de la ciudadanía ayer y hoy, El Colegio de México / CINVESTAV, Departamento de Investigaciones Educativas, México, 2012,pp.191-222.

SOSENSKI, Susana, "Producciones culturales para la infancia mexicana: los juguetes (1950-1960), en Relaciones, Michoacán, 2012, No 132, pp. 95-126.

SZIR, Sandra M., Infancia y cultura visual. Los periódicos ilustrados para niños (1880-1910), Miño y Dávila, 
Buenos Aires, 2006.

VARELA, Mirta, Los hombres ilustres de Billiken. Héroes en los medios y en las escuelas, Colihue, Buenos Aires, 1994.

VIGIL, Constancio C., Mangocho, Editorial Atlántida, Buenos Aires, 1927.

VIGIL, Constancio C., "La otra muñeca y la tuya", en Cartas a Gente Menuda, Talleres Gráficos RBP, Buenos Aires, 1927.

ZAPIOLA, María Carolina, "Los niños en las calles: imágenes literarias y representaciones oficiales en la Argentina del Centenario", en GAYOL, Sandra, MADERO, Marta (editoras) Formas de historia cultural, Prometeo/UNGS, Buenos Aires, 2007, pp. 205-332. 